\title{
A Rare Case of Internal Carotid Artery Aneurysm Presenting as Total Ophthalmoplegia
}

\author{
Sapan Jaiswal1 ${ }^{1}$, Neha Bajpayee ${ }^{2}$, Abhishek G.U. ${ }^{3}$ \\ 1,2,3 Department of Ophthalmology, Jawaharlal Nehru Medical College, Datta Meghe Institute of Medical Sciences \\ (Deemed to Be University), Sawangi (Meghe), Wardha, Maharashtra, India.
}

\section{INTRODUCTION}

Cerebral aneurysms are pathological focal dilatations of cerebral vasculature that are prone to rupture ${ }^{1}$. Pathogenesis involves aberrations of cerebral vasculature resulting in compromised integrity of internal elastic lamina with associated defects in adjacent media and adventia. ${ }^{1}$

Apart from posterior communicating artery aneurysm, internal carotid artery aneurysms account for $4 \%$ of all cerebral aneurysms. ${ }^{2}$ Paraclinoid aneurysms are defined as those originating from the ICA between the infra clinoid portion (C3) and proximal of the posterior communicating artery. Their classification is given by $\mathrm{Al}$ Rodhan $^{3}$ is as follows:

Type Ia - superior hypophyseal, type Ib - ventral paraclinoid, type II - true ophthalmic, type III - carotid cave, type IV - transitional, type V - intra cavernous.

In literature many cases of cerebral aneurysms presenting with visual symptoms have been reported ${ }^{4}$ in which, aneurysms were located on internal carotid artery near ophthalmic artery called as paraclinoid aneurysms.

The unruptured cerebral aneurysms cause mass effect hence producing symptoms of nausea, vomiting and severe headache and later on by compressing surrounding cranial nerves produce ocular symptoms like ophthalmoplegia and ptosis. The aneurysms may rupture and result in intracranial bleed which again by mass effect can produce the above told symptoms.

We report a case of unruptured intracranial aneurysm presenting with total ophthalmoplegia with visual deficit as the primary symptom.

\section{PRESENTATION OF CASE}

A 27-year-old male patient presented to ophthalmology OPD with complaints of diminution of vision in left eye and drooping of left upper eye lid for 1 week. Patient gives a history of acute onset of symptoms which progressed over a period of 1 week. There was no history of trauma, hypertension, diabetes mellitus or any other cardiovascular abnormalities.

\author{
Corresponding Author: \\ Dr. Sapan Jaiswal, \\ Meghdoot Apartments, \\ Datta Meghe Institute of \\ Medical Sciences, Sawangi, \\ Wardha, Maharashtra, India. \\ E-mail: sapanjaiswal554@gmail.com
}

DOI: $10.14260 /$ jemds/2021/100

How to Cite This Article:

Jaiswal S, Bajpayee N, Abhishek GU, et al. A rare case of internal carotid artery aneurysm presenting as total ophthalmoplegia. J Evolution Med Dent Sci 2021;10(07):454-457, DOI:

$10.14260 /$ jemds/2021/100

Submission 13-10-2020,

Peer Review 16-12-2020,

Acceptance 23-12-2020,

Published 15-02-2021.

Copyright (C) 2021 Sapan Jaiswal et al. This is an open access article distributed under Creative Commons Attribution License [Attribution 4.0 International (CC BY 4.0)] 

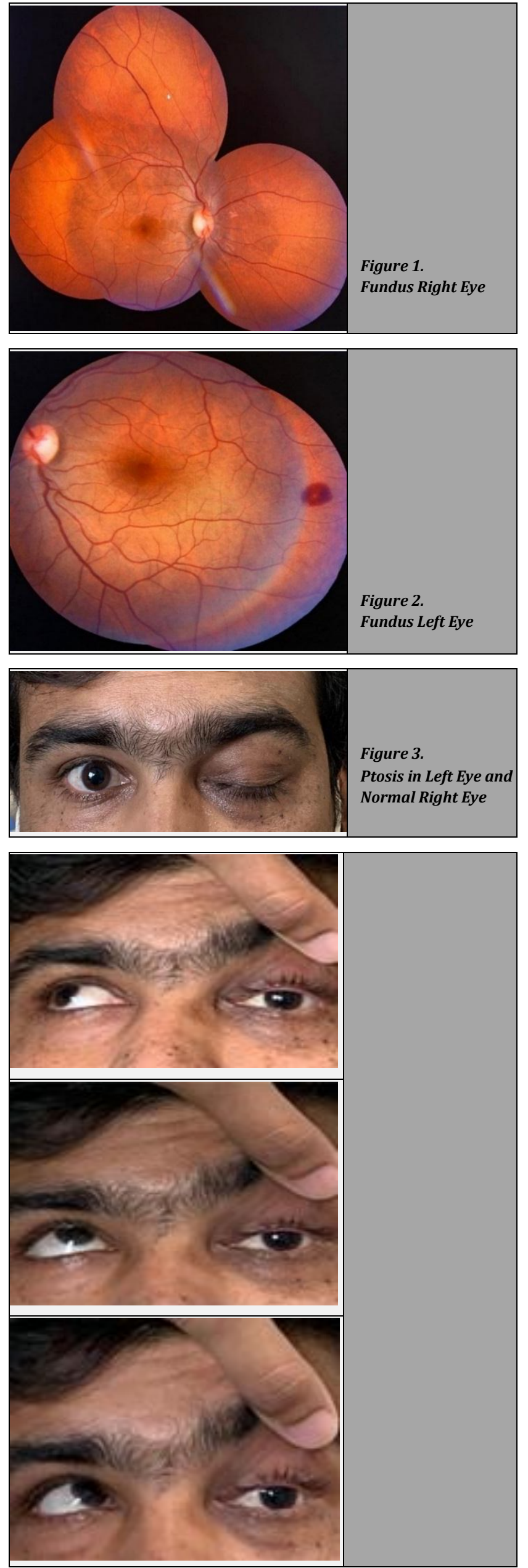

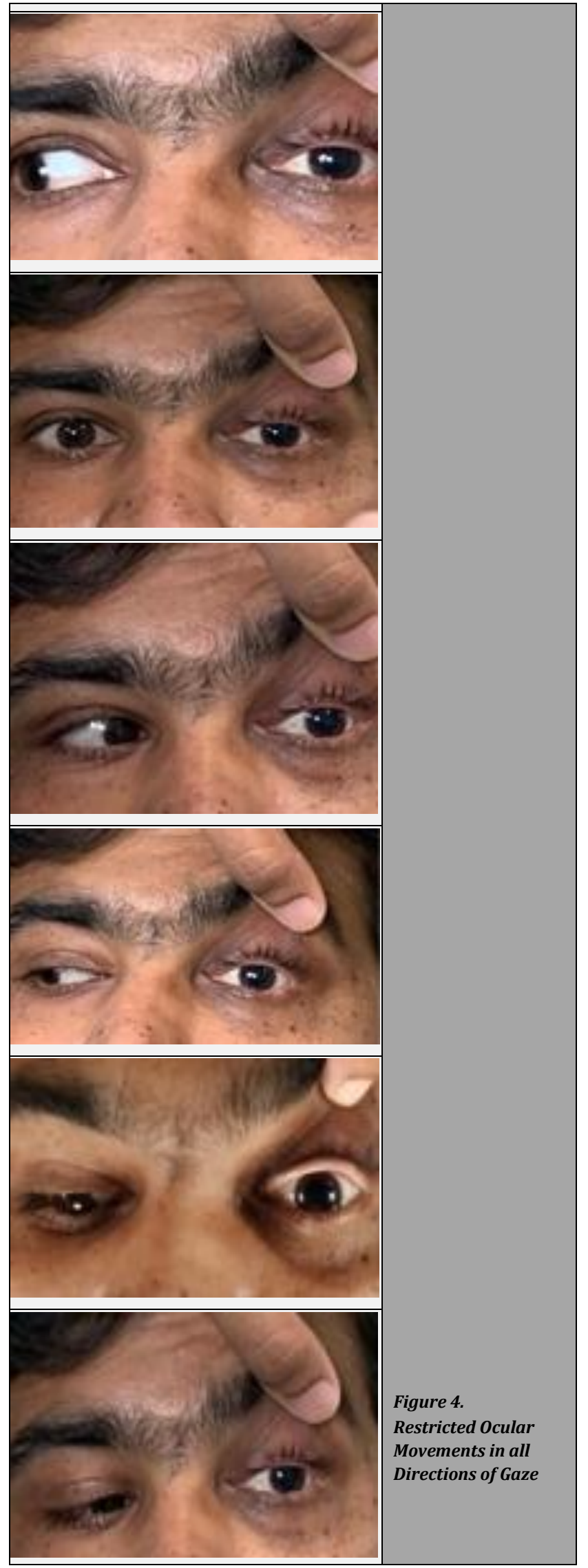

\section{On Examination}

Right Eye

Best corrected visual acuity recorded was 6 / 6 in right eye. Anterior segment examination: within normal limits. Ocular 
movements: free and full in all directions of gaze. Intraocular pressure was $14 \mathrm{~mm}$ hg by applanation tonometry. Fundus examination: clear media, normal disc, normal blood vessels and macula on with bright foveal reflex.

\section{Left Eye}

Best corrected visual acuity recorded was counting fingers 1 metre in left eye. Anterior segment examination: left upper lid showed severe / grade 3 ptosis. Pupil was dilated and not reacting to light. Ocular movements: were restricted in all directions of gaze in left eye. Intraocular pressure was $16 \mathrm{~mm}$ hg by applanation tonometry. Fundus examination: clear media, normal disc, normal vessels and macula was on with bright foveal reflex and a haemorrhagic spot of about half disc diameter noted on peripheral temporal retina.

Contrast enhanced CT was advised which revealed a giant internal carotid artery aneurysm in the cavernous region on left side (Figure 4). Left superior ophthalmic vein dilatation. There was no evident bleeding visible in CT. This large aneurysm was pressing on $3^{\text {rd }}, 4^{\text {th }}$ and $6^{\text {th }}$ cranial nerves on left side resulting in ophthalmoplegia on left side. Patient was further referred for interventional radiology opinion where he was advised for digital subtraction angiography. Further digital subtraction angiography was done to confirm the diagnosis which showed contrast opacification in the region indicating unruptured internal carotid artery aneurysm in left paraclinoid region measuring approximately $8 \mathrm{~mm}$ (Figure 5). Patient's laboratory results including complete blood count, kidney function test, liver function test and coagulation profile were within normal limits.

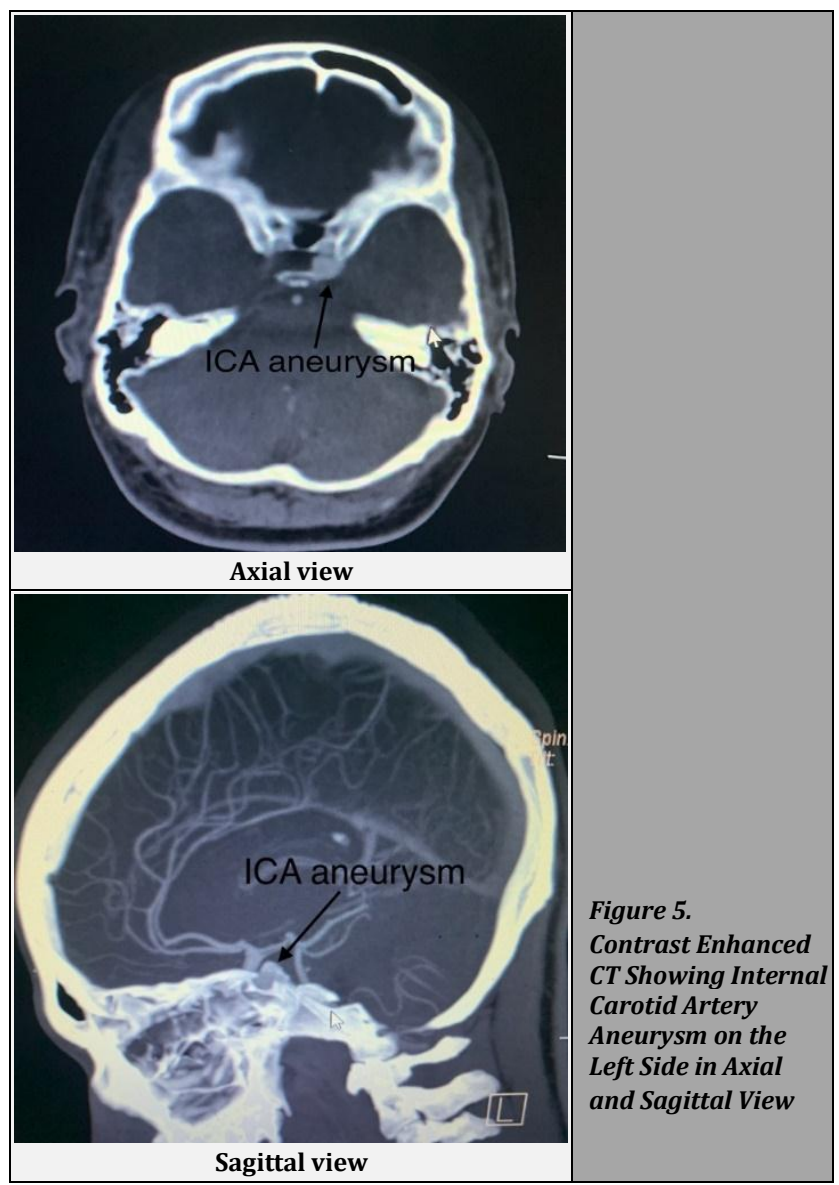

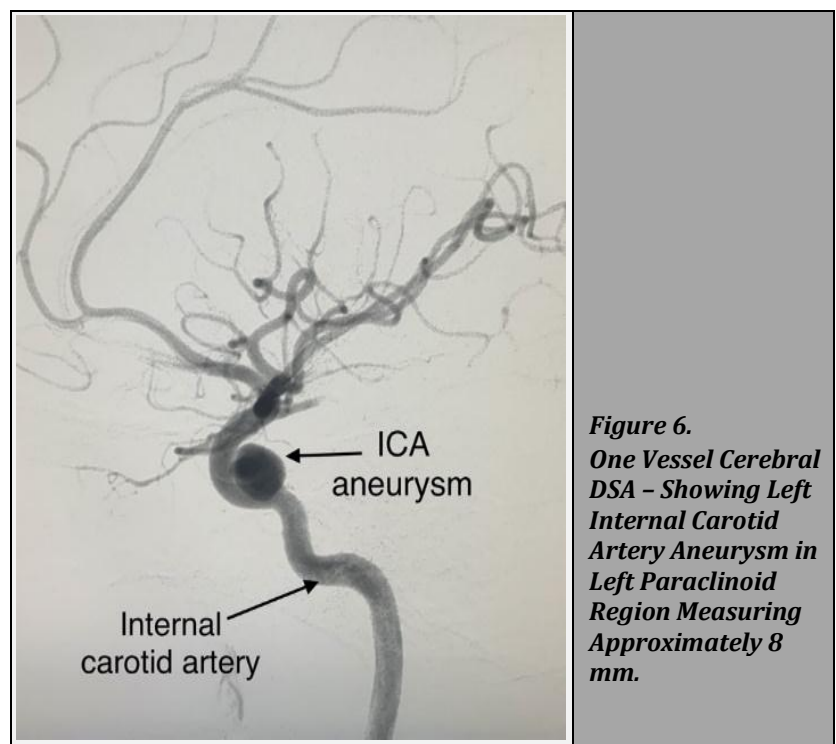

DISCUSSION OF MANAGEMENT

Patient underwent endovascular embolisation by left internal carotid artery aneurysm coiling procedure under local anaesthesia. Cerebral angiogram done post procedure (Figure 6) showed coil noted in situ in paraclinoid region on left side with surrounding metal artefact - indicating successful embolisation and exclusion of aneurysm.

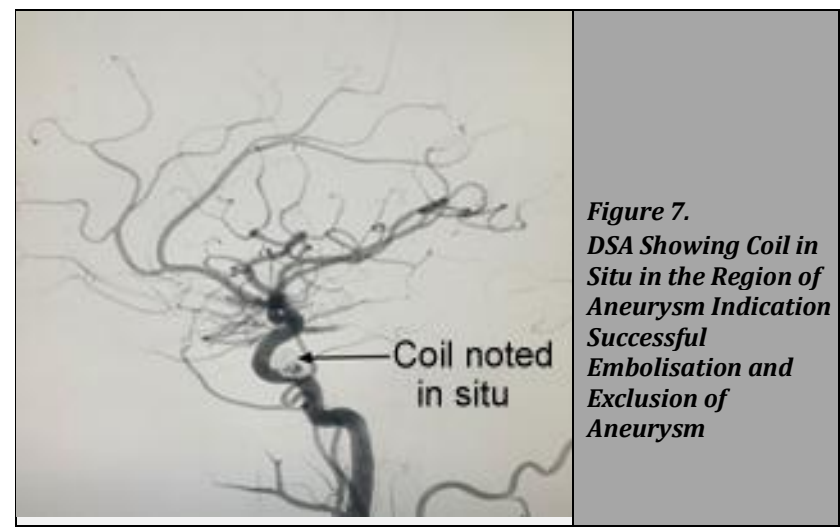

Patient was followed up after 20 days, post endovascular coiling showed improvement in best corrected visual acuity (BCVA) - 6 / 60, ocular movements were improved and ptosis had also improved. Coiling caused exclusion of aneurysm and decompression of $3^{\text {rd }}, 4^{\text {th }}$ and $6^{\text {th }}$ cranial nerves and hence improvement in the symptoms.

\section{DISCUSSION}

Ophthalmoplegia refers to paralysis or weakness of ocular muscles. External ophthalmoplegia is paralysis of external ocular muscles and internal ophthalmoplegia is paralysis of iris and ciliary muscles.7,8 It may be myopathic involving muscles or neurogenic involving nerve pathways that supply the muscle. ${ }^{9}$ Total ophthalmoplegia involves $3^{\text {rd }}, 4^{\text {th }}$ and $6^{\text {th }}$ nerve palsies causing ptosis, restriction of ocular movements and dilated pupil. 
The International Study of Unruptured Intracranial Aneurysms (ISUIA) investigators reported that $15.4 \%$ of patients with UIA present with cranial nerve deficits. ${ }^{10}$ UIA originating from ICA producing visual deficit are less common but have been reported. ${ }^{11}$

The giant ICA aneurysm found in our case was causing ophthalmoplegia secondary to pressure effect / mass effect by compressing $3^{\text {rd }}, 4^{\text {th }}$ and $6^{\text {th }}$ cranial nerves. Intracranial aneurysm in this area is the common aetiology causing ophthalmoplegia in $20-30 \%$ of cases as in a study by Merve Fatma et al.12,130phthalmoplegia due to aneurysm can also occur following rupture of aneurysm and intracranial bleed. In a report by M Enokida et al.,14 ophthalmoplegia following rupture of aneurysm was more common and ophthalmoplegia in unruptured cases of aneurysm was very less.

Reduction of vision can be attributed to involvement of optic nerve due to mass effect on optic pathways. Similar condition was also seen in another case reported by Wonhyoung Park ${ }^{15}$ wherein they compared resolution of visual defects following surgery or endovascular coiling and also seen in a report by Date I et al. ${ }^{4}$

In our case the patient presented with total ophthalmoplegia as a primary presentation who was further advised contrast-enhanced computed tomography (CECT) and an internal carotid artery aneurysm was recognised. Patient was then referred to interventional radiologist who then advised digital subtraction angiography (DSA) and confirmed the diagnosis. Patient underwent endovascular coiling for ICA aneurysm.

Symptomatic unruptured intracranial aneurysm carries higher risk of rupture than asymptomatic UIA and hence requires quick neurosurgical management. Such management can alleviate symptoms and prevent rupture. ${ }^{16}$

Patient in our case underwent endovascular coiling and not surgical clipping. Many cases have been recorded where surgical management of unruptured aneurysms have shown visual recovery and recovery of ophthalmoplegic symptoms. ${ }^{17}$

In another study by Hassan et al. ${ }^{11}$ ophthalmic symptoms secondary to mass effect was reported and majority showed response in the form of visual recovery following endovascular treatment.

\section{CONCLUSIONS}

Such cases where ICA aneurysm presents with ophthalmoplegia as a primary presentation though rare have to be thoroughly investigated. Early intervention of such cases becomes important as it may lead to series of complications like rupture of aneurysm, intracranial bleeding and fistula formation. We aimed for early diagnosis and intervention in one such case and saved the patient from its complication.

Financial or other competing interests: None.

Disclosure forms provided by the authors are available with the full text of this article at jemds.com.

\section{REFERENCES}

[1] Liebeskind DS. Cerebral aneurysms. 2018. https://emedicine.medscape.com/article/1161518overview\#a6
[2] Liebeskind DS. What are internal carotid artery (ICA) aneurysms?

https://www.medscape.com/answers/116151879328/what-are-internal-carotid-artery-ica-aneurysms

[3] Al-Rodhan NR, Piepgras DG, Sundt TM. Transitional cavernous aneurysms of the internal carotid artery. Neurosurgery 1993;33(6):997-8.

[4] Date I, Asari S, Ohmoto T. Cerebral aneurysms causing visual symptoms: their features and surgical outcome. Clin Neurol Neurosurg 1998;100(4):259-67.

[5] Nishino A, Sakurai Y, Arai H, et al. Clinical manifestations, character of aneurysms and surgical results for unruptured cerebral aneurysms presenting with ophthalmic symptoms. Acta Neurochir Suppl 2002;82:479.

[6] Rizzo JF. Visual loss after neurosurgical repair of paraclinoid aneurysms. Ophthalmology 1995;102(6):905-10.

[7] Man CYYW, Smith T, Chinnery PF, et al. Assessment of visual function in chronic progressive external ophthalmoplegia. Eye (Lond) 2006;20(5):564-8.

[8] Das S. Total ophthalmoplegia - a series of case reports. Delhi Journal of Opthalmology 2020;30:67-71.

[9] Wolter JR. Neuro-ophthalmology. In: Duke-Elder S, Scott GI, eds. System of ophthalmology. Part - 2. Vol. 12. St. Louis: CV Mosby 1971: p. 780.

[10] International Study of Unruptured Intracranial Aneurysms Investigators. Unruptured intracranial aneurysms - risk of rupture and risks of surgical intervention. N Engl J Med 1998;339(24):1725-33.

[11] Hassan T, Hamimi A. Successful endovascular management of brain aneurysms presenting with mass effect and cranial nerve palsy. Neurosurg Rev 2013;36(1):87-97.

[12] Evliyaoğlu C. Pathophysiology and genetics of intracranial aneurysms. Turkish Neurosurgery 2012;22:189-96.

[13] Bozkurt MF, Dinc E, Eken E, et al. A rare cause of sudden ptosis: posterior communicating artery aneurysm. Turk J Emerg Med 2015;15(2):90-2.

[14] Enokida M, Sakurai Y, Sato T, et al. Oculomotor palsy caused by aneurysms at the internal carotid-posterior communicating artery junction and its prognosis following intracranial surgery (author's transl). No to Shinkei 1978;30(7):789-93.

[15] Park W, Park JC, Han K, et al. Anterior optic pathway compression due to internal carotid artery aneurysms: neurosurgical management and outcomes.J Stroke 2015;17(3):344-53.

[16] de Oliveira JG, Borba LA, Rassi-Neto A, et al. Intracranial aneurysms presenting with mass effect over the anterior optic pathways: neurosurgical management and outcomes. Neurosurg Focus 2009;26(5):E3.

[17] Nonaka T, Haraguchi $K$, Baba $T$, et al. Clinical manifestations and surgical results for paraclinoid cerebral aneurysms presenting with visual symptoms. Surg Neurol 2007;67(6):612-9. 